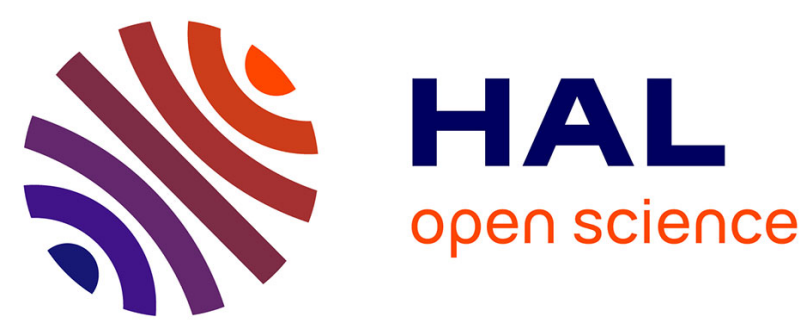

\title{
Simulation and design of a three-stage metal hydride hydrogen compressor based on experimental thermodynamic data
}

\author{
A.R. Galvis E, F. Leardini, J.R. Ares, Fermin Cuevas, J.-F. Fernandez
}

\section{To cite this version:}

A.R. Galvis E, F. Leardini, J.R. Ares, Fermin Cuevas, J.-F. Fernandez. Simulation and design of a three-stage metal hydride hydrogen compressor based on experimental thermodynamic data. International Journal of Hydrogen Energy, 2018, 43 (13), pp.6666-6676. 10.1016/j.ijhydene.2018.02.052 . hal-02054365

\section{HAL Id: hal-02054365 \\ https://hal.science/hal-02054365}

Submitted on 28 Jul 2021

HAL is a multi-disciplinary open access archive for the deposit and dissemination of scientific research documents, whether they are published or not. The documents may come from teaching and research institutions in France or abroad, or from public or private research centers.
L'archive ouverte pluridisciplinaire HAL, est destinée au dépôt et à la diffusion de documents scientifiques de niveau recherche, publiés ou non, émanant des établissements d'enseignement et de recherche français ou étrangers, des laboratoires publics ou privés. 


\title{
Simulation and design of a three-stage metal hydride hydrogen compressor based on experimental thermodynamic data
}

\author{
A.R. Galvis E. ${ }^{1}$, F. Leardini ${ }^{1}$, J.R. Ares ${ }^{1}$, F. Cuevas ${ }^{2}$, J.F. Fernandez ${ }^{1}$ \\ ${ }^{1}$ MIRE-Group, Dpto. Física de Materiales, Facultad de Ciencias, Universidad Autónoma de \\ Madrid, 28049 Madrid, Spain. \\ ${ }^{2}$ Université Paris Est, ICMPE (UMR7182), CNRS, UPEC, F-94320, Thiais, France
}

\begin{abstract}
A semi-empirical method was developed to design a three stage Metal Hydride Hydrogen Compressor (MHHC) through the determination of thermodynamic properties of several hydrides. As a first step, three $\mathrm{AB}_{2}$-type alloys that satisfy operation conditions were selected from published thermodynamic data entailing over 200 single plateau hydrides. These alloys were synthetized by arc melting and characterized by X-Ray Powder Diffraction (XRPD), Scanning Electron Microscopy (SEM) and Energy Dispersion X-ray spectroscopy (EDX). Absorption and desorption Pressure-composition-Isotherms (P-c-I) were determined between 23 and $80{ }^{\circ} \mathrm{C}$ to characterize their thermodynamic properties. Subsequently, an algorithm that uses these experimental data and a real equation of state for gaseous $\mathrm{H}_{2}$ was implemented to simulate the volume, alloy mass, pressure and temperature of operation for each compressor stage, while optimizing the compression ratio and total number of compressed $\mathrm{H}_{2}$ moles. Optimal desorption temperatures for the three stages were identified within the range of 110 to $132{ }^{\circ} \mathrm{C}$. A system compression ratio (CR) of 92 was achieved. The number of $\mathrm{H}_{2}$ moles compressed, the alloy mass and volume of each stage depend linearly on the volume of the external tank in which the hydrogen is delivered.
\end{abstract}

Key Words: $\mathrm{AB}_{2}$ intermetallic hydrides, Hydride compressor, Thermodynamics, Semiempirical modelling

\section{Introduction}

The urgency to replace fossil fuels by sustainable renewable ones has increased the research on novel technologies. Between several choices, hydrogen excels as an energy vector that can help to reduce greenhouse gases thanks to its high energy content and diversified sources of supply $[1,2]$. Key features in the hydrogen cycle are its production, transport and storage [3, 4]. On this regard, hydrogen compressors provide an excellent approach to integrate the production and storage with the distribution of hydrogen as an energy carrier for different applications [5-7]. Specifically, Metal Hydride Hydrogen Compressors (MHHC) give great improvements in comparison to other compression technologies and therefore have focused much attention in recent years $[5,6]$.

Several approaches have been followed to enhance MHHC performances [5]. Simulations are particularly useful to predict and design hydrogen sorption and thermal management in Metal Hydride (MH) tanks, including MHHC. Hardy et al. [8] developed a hierarchical methodology for modeling hydrogen storage systems, in which finite element models (FEM) were used to simulate and optimize the hydrogen sorption properties of a cylindrical hydrogen storage tank containing sodium alanate with a shell and tube type heat exchanger. Although the model gave proper results, some realistic features such as hysteresis and the volume expansion of the complex hydride during sorption were not taken into account and the system geometry required further optimization. Førde et al. [9] developed a one-dimensional heat and mass transfer model with an ideal equation of state (EOS) for a MH-based hydrogen storage system. It was validated with experimental results from a $\mathrm{La}_{0.83} \mathrm{Ce}_{0.10} \mathrm{Pr}_{0.04} \mathrm{Nd}_{0.03} \mathrm{Ni}_{4.4} \mathrm{Al}_{0.60}$ alloy at different temperatures and hydrogenation pressures. This model exhibited a higher sensitivity to kinetic and thermal parameters such as the activation energy, effective thermal conductivity and heat of the reaction 
than with other operational variables described. Gkanas et al. [10] optimized the compression ratio by combining hydride materials $\mathrm{AB}_{5}\left(\mathrm{LaNi}_{5}\right.$ and $\left.\mathrm{MmNi}_{4.6} \mathrm{Al}_{0.4}\right)$ and $\mathrm{AB}_{2}(\mathrm{Zr}-\mathrm{V}-\mathrm{Mn}-\mathrm{Nb}$ and Ti-Zr-V-Fe-Cr-Mn) for the first and second stage of the compressor, while maximizing the hydrogen rate using numerical simulations to predict the real behavior of the system.

Moreover, some prototypes and experimental approaches have been developed. Laurencelle et al. [11], designed a three-stage $\mathrm{AB}_{5}$ MHHC prototype for a hydrogen production facility using a low-pressure alkaline electrolyzer. The materials selected for the system were $\mathrm{LaNi}_{4.8} \mathrm{Sn}_{0.2}$, $\mathrm{LaNi}_{5}$ and $\mathrm{MmNi}_{4.7} \mathrm{Al}_{0.3}$ for the first, second and third stage respectively, where it performs a thermal cycling between 20 and $80{ }^{\circ} \mathrm{C}$ with a flow rate that reaches about $20 \mathrm{~L}$ (NTP) of hydrogen per hour. Vanhanen et al. [12] studied the feasibility of combined MHHC and heat pump through the characterization of various alloys. The used alloys for both compression and heat pump were the Hydralloy $\mathrm{C} 2$ and Hydralloy $\mathrm{C} 0$ for the first and second stage, respectively. Although, the hydrogen pressure increased from 12-18 bar up to $85-110$ bar by utilizing a very narrow temperature interval $\left(20-60^{\circ} \mathrm{C}\right)$, if a third alloy $\left(\mathrm{TiCrMn}_{0.55} \mathrm{Fe}_{0.33} \mathrm{~V}_{0.15}\right)$ was added, then the hydrogen pressure could reach almost 199 bar. As a result, a three stage MHHC gave greater results than just a two stage one. Wang et al. [13] developed a two-stage 700 bar hydride compressor using $\mathrm{AB}_{2}$ hydrides by comparing the thermodynamic behavior of different compositions of the $\mathrm{AB}_{2}$ alloys Ti-Cr-Mn and Ti-Zr-Cr-Fe-V, for the first and second stage of the compressor respectively. With exchanging cold oil $(298 \mathrm{~K})$ and hot oil $(423 \mathrm{~K})$, the built compression system could convert hydrogen pressure from around 40 bar to over 700 bar. Lototsky et al. [14] created a prototype MH compressor operating in a temperature range 20 to $150^{\circ} \mathrm{C}$ and providing compression of hydrogen from 10 to 200 bar with an average productivity up to $1 \mathrm{~m}^{3} / \mathrm{h}$. The compressor has a two stage layout where the first part uses $\mathrm{AB}_{5^{-}}$and the second $\mathrm{AB}_{2}$-type hydride-forming intermetallic compounds. Bhuiya et al. [15] made an experiment-driven design procedure in order to optimize the parameters between stages in a dual-stage hydrogen compressor and subsequently achieved an enhanced compression ratio. The compressor system was composed by a $\mathrm{LaNi}_{5}$ in the first stage and a $\mathrm{Ca}_{0.2} \mathrm{Mm}_{0.8} \mathrm{Ni}_{5}$ in the second one, obtaining a higher couple compression ratio (53\%) than the one acquired with just the hydride of the first stage. Muthukumar et al. [16] performed experimental tests on a $\mathrm{MmNi}_{4.6} \mathrm{Al}_{0.4}$ based hydrogen compressor by varying operating parameters such as supply pressure and heating temperature under constant and variable delivery pressures with different storage volumes. Hydrogen storage pressure increases with a rise in the supply pressure and heating temperature. In the best conditions studied, with a variable $\mathrm{H} 2$ delivery a maximum isentropic efficiency of $7.3 \%$ is obtained at a CR of $8.8(43.8 / 5$ bar $)$ and $95^{\circ} \mathrm{C}$ hot fluid temperature, while with a constant delivery, the corresponding efficiency is $14.2 \%$, the CR is 3 (30/10 bar) and the hot fluid is at $85^{\circ} \mathrm{C}$. To summarize, previous studies are focused in the best combination of alloys at different stages of compression while searching the enhancement of the kinetics through geometry optimization.

Unfortunately, several MHHC works disregard many important thermodynamic features such as sloping plateau and hysteresis during the metal-hydrogen reaction or the use of real $\mathrm{H}_{2}$ equation of state (EOS). Moreover, they only considered the combination of a few materials, though the thermodynamics of many $\mathrm{MH}$ are reported in the literature [5,17]. On this regard, Voskuilen et al. [18] developed an interesting approach by creating a fairly conscious data base of $\mathrm{MH}$ and the use of a simple numerical model to select a combination of materials for a two-hydride thermal system, specifically a heat pump. Thermophysical and kinetic properties of the alloys selected were considered to optimize a key system parameter like the Coefficient of Performance (COP).

The novelty of the present work is twofold. Firstly, the implementation of more than 200 alloys for a selection program, aids to ensure that the materials selected are an optimum combination for MHHC design. Secondly, real $\mathrm{H}_{2}$ gas EOS as well as experimental features of the alloys (i.e. sloping plateau, hysteresis, and variation of the 
reversible capacity with temperature) were considered to account for the real behavior of these materials and their combined influence in the final outcome of the system.

As a result, a new methodology is developed for improving the selection of materials for a MHHC system and, therefore, its performance. In the first part of the study, thermophysical data from literature and operational parameters of the compressor are considered to select the proper materials trough a simple model based on ideal thermodynamics. Then, the selected materials were synthesized and characterized chemically, structurally and thermodynamically. Finally, an algorithm that considers the realistic thermodynamic models and real gas $\mathrm{H}_{2}$ EOS is implemented to define and optimize some parameters of the MHHC system (i.e., volume and alloy mass of each stage) to deliver the greatest quantity of hydrogen compressed at the highest compression ratio.

\section{Materials and methodology}

First of all, the thermophysical properties of more than 200 alloys from a data base [18] and literature studies [19-39] were considered to implement a selection program for a three-stage MHHC. The operational parameters of the system were considered as described in section 2.1. The selected materials were synthesized and characterized as detailed in section 2.2. Finally, the Pressure-composition Isotherms (P-c-I) determined experimentally are the main input of a Matlab $^{\mathrm{TM}}$ program that uses realistic thermodynamic features of the hydrides and real EOS to design each stage of compression so that the final compression ratio and number of moles compressed can be optimized, as it is described in section 2.3.

\subsection{First numerical approach}

Several single-plateau metal hydride compounds were first selected for each stage of the compressor based on the thermodynamic properties of each alloy. Also, they were constrained according to the operational parameters of the system, such as: $i$ ) working temperature and inlet pressure of the compressor system (between room temperature $\left(\left(\mathrm{RT} \approx 23^{\circ} \mathrm{C}\right)-150{ }^{\circ} \mathrm{C}\right.$, and around 1 bar, respectively), ii) an ideal compression ratio $(\mathrm{CR}=$ [desorption pressure at high temperature / absorption pressure at low temperature] $>8$ between coupling stages, i.e. first and second). Similarly, some criteria were included in the algorithm: iii) Van't Hoff derived plateau pressure (without slope), iv) hysteresis ( $\ln [$ Pplateau (abs) / Pplateau (des)]). Finally, the possibility of tuning of the thermodynamic properties of the hydrides by modifying their chemical composition was the final criteria to select the materials.

The first selection of the algorithm is made by comparing for each hydride reported the temperatures of operation and related plateau pressures with the established range at which the compressor works. Then, for the selected compounds, the published enthalpy and entropy of formation [18-39] are employed to generate Van't Hoff plots both for absorption and desorption. For materials for which data is only provided on absorption or desorption, an average value of hysteresis is applied [18] depending on the hydride type $\left(\mathrm{AB}, \mathrm{AB}_{2}, \mathrm{AB}_{5} \ldots\right)$ to obtain the respective absorption/desorption Van't Hoff plots. Then, several alloys were selected for the first stage based on the constraint that the inlet pressure $\left(\mathrm{P}_{\mathrm{in}}\right)$ at RT should be slightly above 1 bar. Similarly, for the third stage, alloys with desorption pressures as high as possible at temperatures $<150^{\circ} \mathrm{C}$ were identified. Subsequently, the second stage alloy has to accomplish that its desorption pressure at high temperature should be equal or greater than the absorption pressure of the third alloy at RT. Analogously, the desorption pressure of the first stage have to be equal or greater than the absorption pressure of the second alloy at RT. Several combinations of alloys fulfilling these conditions were found. The final selection was taken by choosing alloys of close chemical composition so that by tuning a small quantity of their constituting elements, the final thermodynamic properties can be properly modified. As a result, three compounds, a low pressure (LP), a medium pressure (MP) and a high pressure (HP) hydride were selected as the ideal final combination of alloys that achieves all of the requirements proposed above. 


\subsection{Experimental approach}

The three samples selected for the compressor were synthesized by arc melting of raw elements (with a purity of $\mathrm{Ti}=99.99 \%, \mathrm{Zr}=99.5 \%, \mathrm{Mn}=99.9 \%, \mathrm{Cr}=99.2 \%, \mathrm{~V}=99.7 \%$ ) under an argon atmosphere of 0.7 bar. $6 \%$ weight in excess of Mn was used for all synthesis. The melted ingots were turned at least 5 times to ensure homogeneous composition. Their microstructure and elemental chemical composition were analyzed by Scanning Electron Microscopy (SEM, Hitachi S-3000N OK) and Energy Dispersive X-ray spectroscopy (EDX), respectively. X-ray Powder Diffraction (XRPD, PANALYTICAL X'pert PRO $\theta-2 \theta$ ) analysis with $\mathrm{Cu}-\mathrm{K}_{\alpha}$ radiation in a $\theta-2 \theta$ configuration and a further Rietveld refinement were performed to determine phase amounts, lattice constants and crystal density. P-c-I absorption and desorption curves were determined with a real gas $\mathrm{H}_{2}$ EOS [40] and the data measured in a thermalized home-made Sieverts-type volumetric reactor at three different temperatures, 23,50 and $80{ }^{\circ} \mathrm{C}$. The samples were manually grinded by agate mortar and pestle, sieved under $45 \mu \mathrm{m}$ in Ar atmosphere and subsequently placed in the Sieverts reactor. The activation of all samples was performed by three absorption/desorption cycles at room temperature $\left(23^{\circ} \mathrm{C}\right)$, and at a pressure of 25 bar for the alloy $\mathrm{M} 1=\mathrm{Ti}_{0.85} \mathrm{Zr}_{0.15} \mathrm{Mn}_{1.33} \mathrm{~V}_{0.3} \quad(0.566(1)$ gr) and of 50 bar for the alloys $\mathrm{M} 2=\mathrm{Ti}_{0.8} \mathrm{Zr}_{0.2} \mathrm{Mn}_{1.2} \mathrm{Cr}_{0.6} \mathrm{~V}_{0.2}\left(0.556(1)\right.$ gr) and $\mathrm{M} 3=\mathrm{Ti}_{0.9} \mathrm{Zr}_{0.1} \mathrm{Mn}_{1.4} \mathrm{Cr}_{0.4} \mathrm{~V}_{0.2}(0.516(1) \mathrm{gr})$.

\subsection{Second numerical approach}

As final step, an algorithm in Matlab ${ }^{\mathrm{TM}}$ was implemented to simulate different operational variables of the compressor. The main input to the program comprises either experimental and/or simulated P-c-I curves at the selected temperatures of MHHC operation. Simulation of Pc-I curves uses the model developed by Fang et al. [41]. This model fits accurately the three main regions of the P-c-I curves with two equations that consider their variation with temperature $[41,42]$. The first equation is a modification of the Sievert's law that simulates the solid-solution branch, i.e. the alpha $(\alpha)$ and beta $(\beta)$ phases. The second one models the plateau pressure, i.e. the biphasic $\alpha+\beta$ region. For each equation, several mathematical coefficients have to be found to simulate the P-c-I at low and high temperature. Also, considerations and constraints have been taken into account for the simulation: (1) The scheme of the whole system (Fig.1) involves three stages of compression, and an external vessel volume $\left(\mathrm{V}_{\text {ext }}\right)$ connected to the third stage where the $\mathrm{H}_{2}$ will be compressed to; (2) the $\mathrm{P}_{\text {in }}$ generates directly the minimum concentration in the beta phase $\left(\beta_{\min }\right)$ in each hydride at RT; (3) the desorption point (pressure and hydrogen content in the P-c-I) at each stage will be the one corresponding to the maximum concentration in the alpha phase $\left(\alpha_{\max }\right)$, and, its pressure $\left(\mathrm{P}_{\text {des }}\right)$ would have to be equal or greater than the absorption pressure $\left(\mathrm{P}_{\mathrm{abs}}\right)$ of the following stage at RT; (4) The final desorption point, at the third stage, will determine the optimum high temperature value (HT) that enhances the CR and final number of $\mathrm{H}_{2}$ moles compressed ( $\mathrm{n}_{\mathrm{H} 2-\mathrm{C}}$ ); (5) A 65\% filling density of the hydrogenated material density is used taking into account former studies on these type of materials [43]; (6) the mass (m) and volume ( $\mathrm{SVol}$ ) of the reactor at each stage are also linked to $\mathrm{V}_{\text {ext }}$ where the $\mathrm{H}_{2}$ will be compressed, hence, this volume will be another parameter to vary in order to observed its effect in the quantity of mass and reactor volumes at each stage; (7) the hydride is in thermal equilibrium with the surrounding gas; (8) a dead volume was considered at each stage due to connection tubes, valves and others $\left(15.4(5) \mathrm{cm}^{3} / \mathrm{stage}\right.$ ); (9) real $\mathrm{H}_{2}$ gas EOS is also implemented [40].

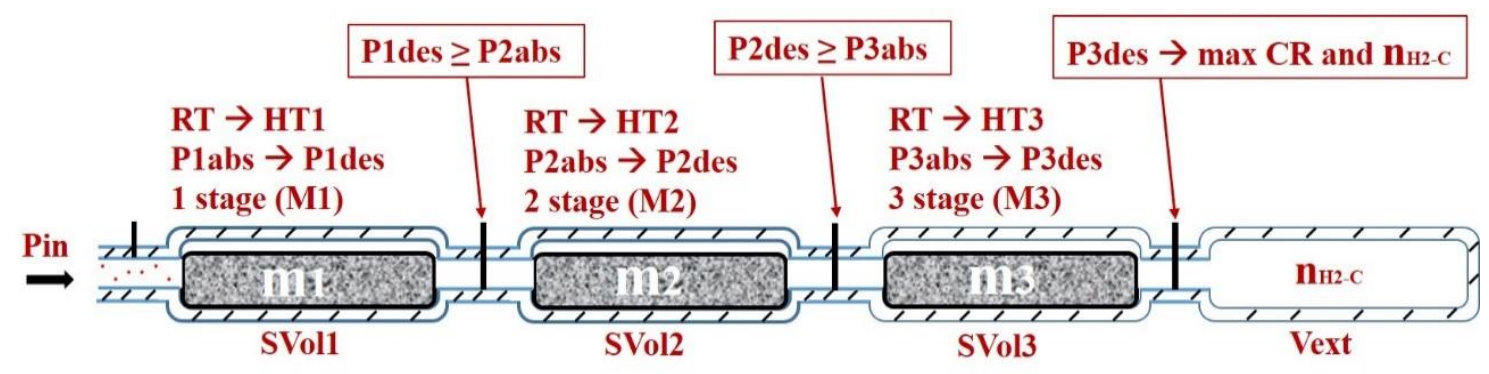

Fig.1. MHHC design scheme. Numbers indicate each consecutive stage up to $V_{\text {ext }}$. 


\section{Results and discussions}

\subsection{Material selection from first numerical approach.}

Fig.2 presents a Van't Hoff plot from the selected hydrides [17, 32] and the operational points of the three stages. The materials selected by the algorithm were the $\mathrm{Ti}_{0.9} \mathrm{Zr}_{0.1} \mathrm{Mn}_{1.3} \mathrm{~V}_{0.3}$ (LP), the $\mathrm{Ti}_{0.8} \mathrm{Zr}_{0.2} \mathrm{Mn}_{1.2} \mathrm{Cr}_{0.6} \mathrm{~V}_{0.2}$ (MP) and the $\mathrm{Ti}_{0.9} \mathrm{Zr}_{0.1} \mathrm{Mn}_{1.4} \mathrm{Cr}_{0.4} \mathrm{~V}_{0.2}$ (HP). The selected alloys are $\mathrm{AB}_{2}$ type, with compositions differing from those used by Vanhanen et al. in the design of a comparable MHHC system [12].

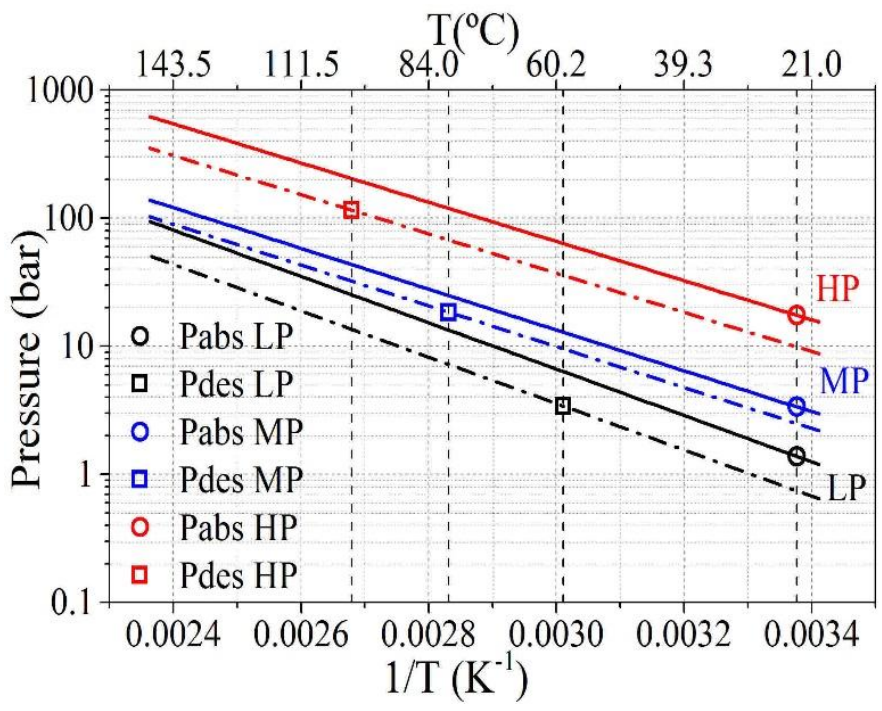

Fig.2. Van't Hoff plot of the three selected alloys. The absorption (solid lines) and desorption (dash lines) curves can be seen for the LP (black), the MP (blue) and the HP (red) compounds. The open circles in each material represent the inlet absorption pressure at each stage and at $23^{\circ} \mathrm{C}$, while the open squares are the pressures of desorption at $59^{\circ} \mathrm{C}, 80^{\circ} \mathrm{C}$ and $100^{\circ} \mathrm{C}$ for the $\mathrm{LP}, \mathrm{MP}$ and $\mathrm{HP}$ alloys respectively.

Fig.2 shows that for each alloy the desorption pressure at high temperature (open squares) matches with the absorption pressure at $23^{\circ} \mathrm{C}$ (open circles) of the alloy used in the subsequent stage. This ideally couples the first to the second and the second to the third stages. Also in Table 1, the main ideal values found for the three materials can be observed.

Table 1. Main results found by the selection algorithm for the three alloys

\begin{tabular}{ccccc}
\hline $\begin{array}{c}\text { Stage / } \\
\text { material }\end{array}$ & $\begin{array}{c}\text { Absorption } \\
\text { pressure @ } \\
\mathbf{2 3}^{\circ} \mathbf{C} \text { (bar) }\end{array}$ & $\begin{array}{c}\text { Desorption } \\
\text { pressure } \\
(\text { bar })\end{array}$ & $\begin{array}{c}\text { Desorption } \\
\text { temperature } \\
\left({ }^{\circ} \mathbf{C}\right)\end{array}$ & $\begin{array}{c}\text { CR between } \\
\text { stages }\end{array}$ \\
\hline 1 / LP & 1.4 & 3.4 & 59 & $1-2: 13.1$ \\
2 / MP & 3.3 & 18.4 & 80 & $2-3: 34.9$ \\
3 / HP & 17.5 & 115.4 & 100 & $1-3: 82.4$ \\
\hline
\end{tabular}

The CR achieved between stages is always greater than 8 , as stablished before. It is worth highlighting that the three alloys are $\mathrm{TiMn}_{2}$-based, for which small compositional changes give rise to strong modifications of the Van't Hoff plots (Fig.2). The combination of these alloys fulfills all of the parameters established previously for this approach.

\subsection{Microstructure and composition of the alloys}

Fig.3 shows the Rietveld refinement of the XRPD data for the three samples, showing the characteristic hexagonal C14-type Laves phase (SG $P 6_{3} / m m c ; \mathrm{N}^{\circ} 194$ ) of $\mathrm{TiMn}_{2}$ based alloys [44-47]. The fact that the main phase of the three alloys crystallize in the same structural type concurs with previous reports showing that $\mathrm{TiMn}_{2} \mathrm{AB}_{2}$-type alloys can accommodate a wide stoichiometric ratio $(1.2 \leq \mathrm{B} / \mathrm{A} \leq 2)$ without changing their structural order $[48,49]$. 

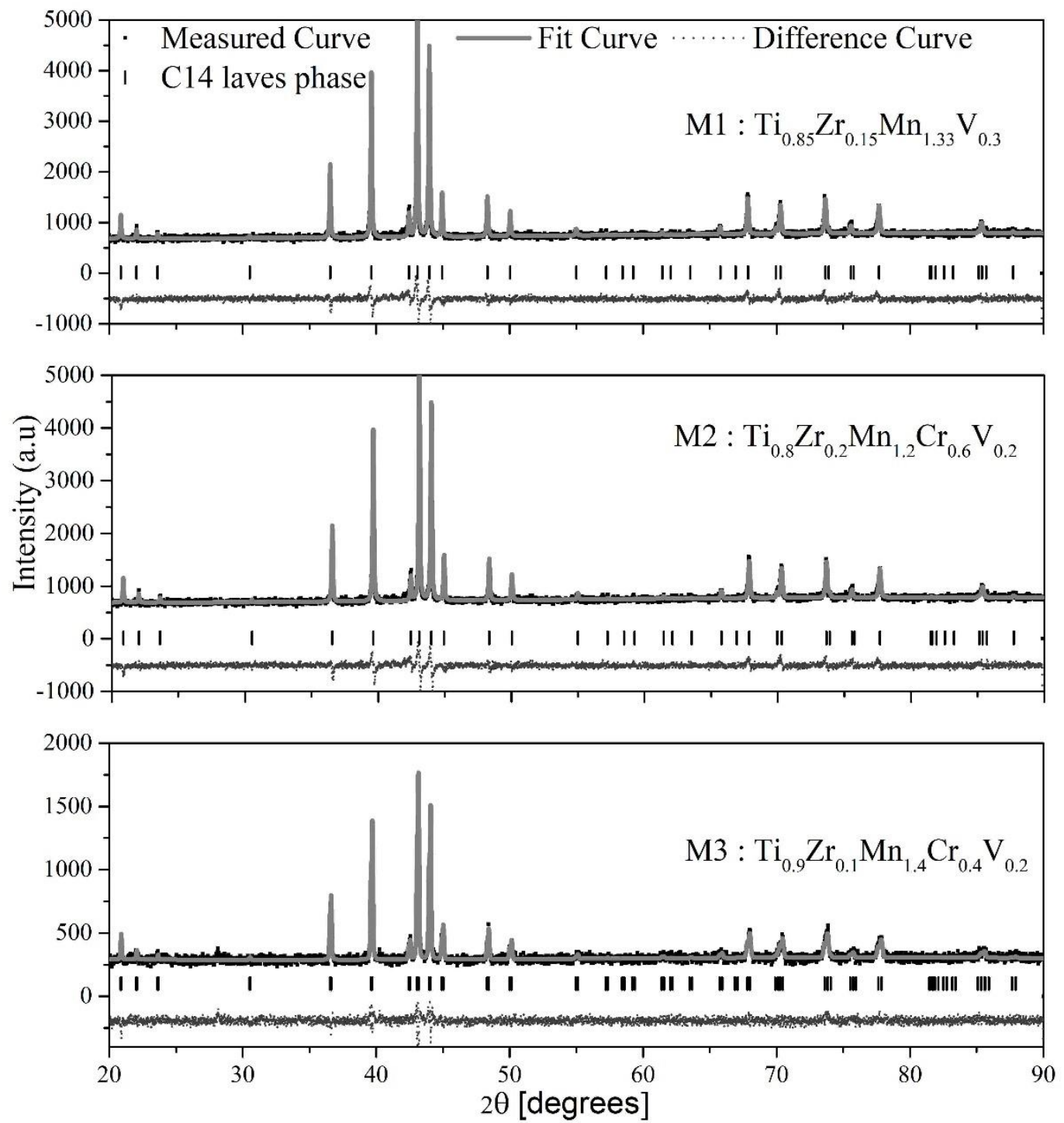

Fig.3. X-ray diffractograms with Rietveld refinement of M1, M2 and M3

The lattice parameters of the main $\mathrm{AB}_{2}$ phase are gathered in Table 2. Clearly the cell volume gradually decreases as $168.6 \mathrm{~cm}^{3}, 167.6 \mathrm{~cm}^{3}$ and $165.5 \mathrm{~cm}^{3}$ for M1, M2 and M3, respectively. This variation of the unit cell volume parameters agrees with empirical geometric laws on the correlation between thermodynamic properties and the cell volume of the alloys [50]. Furthermore, the alloy chemical compositions obtained by EDX analysis are gathered in Table 2 while in Fig. 4 back-scattered electron images of the alloys can be seen.

Table 2. Average stoichiometry and lattice parameters of the C14-type Laves phase for M1, M2 and M3

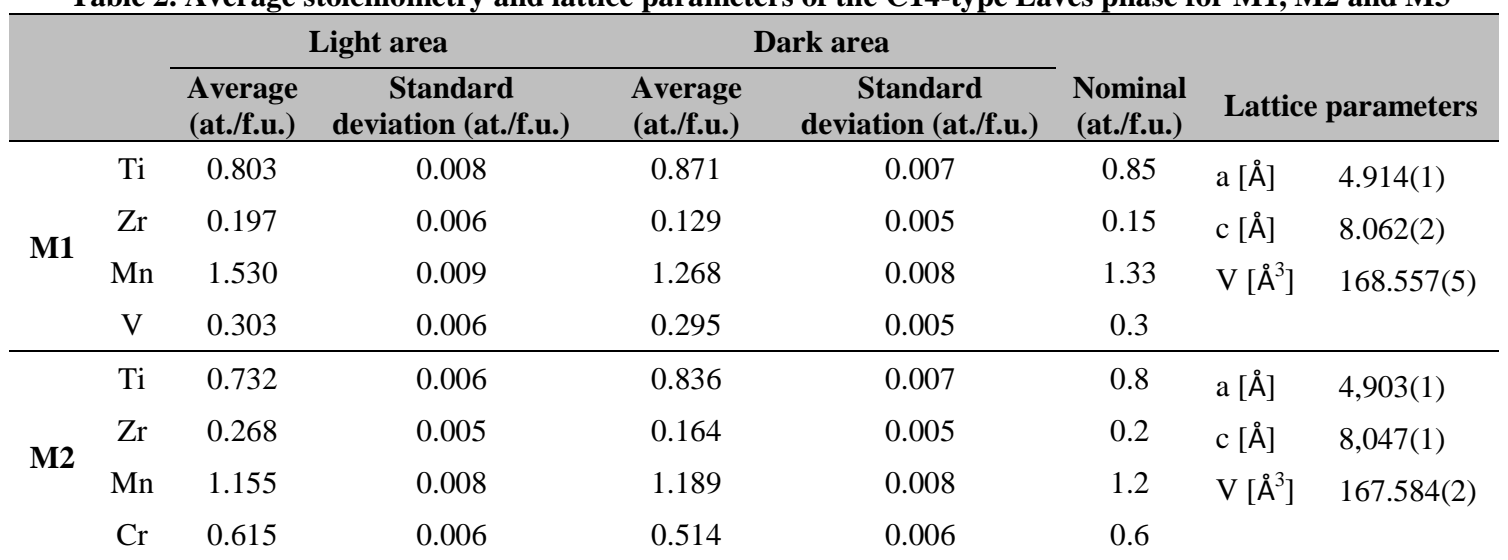




\begin{tabular}{ccccccccl} 
& $\mathrm{V}$ & 0.174 & 0.004 & 0.223 & 0.005 & 0.2 & & \\
\hline & $\mathrm{Ti}$ & 0.882 & 0.007 & 0.938 & 0.007 & 0.9 & $\mathrm{a}[\AA \AA \AA$ & $4,883(1)$ \\
& $\mathrm{Zr}$ & 0.118 & 0.005 & 0.062 & 0.004 & 0,1 & $\mathrm{c}[\AA ̊ \AA$ & $8,014(2)$ \\
$\mathbf{M 3}$ & $\mathrm{Mn}$ & 1.373 & 0.008 & 1.375 & 0.008 & 1.4 & $\mathrm{~V}\left[\AA^{3}\right]$ & $165.478(6)$ \\
& $\mathrm{Cr}$ & 0.436 & 0.006 & 0.280 & 0.005 & 0.4 & & \\
& $\mathrm{~V}$ & 0.180 & 0.005 & 0.246 & 0.005 & 0.2 & & \\
\hline
\end{tabular}

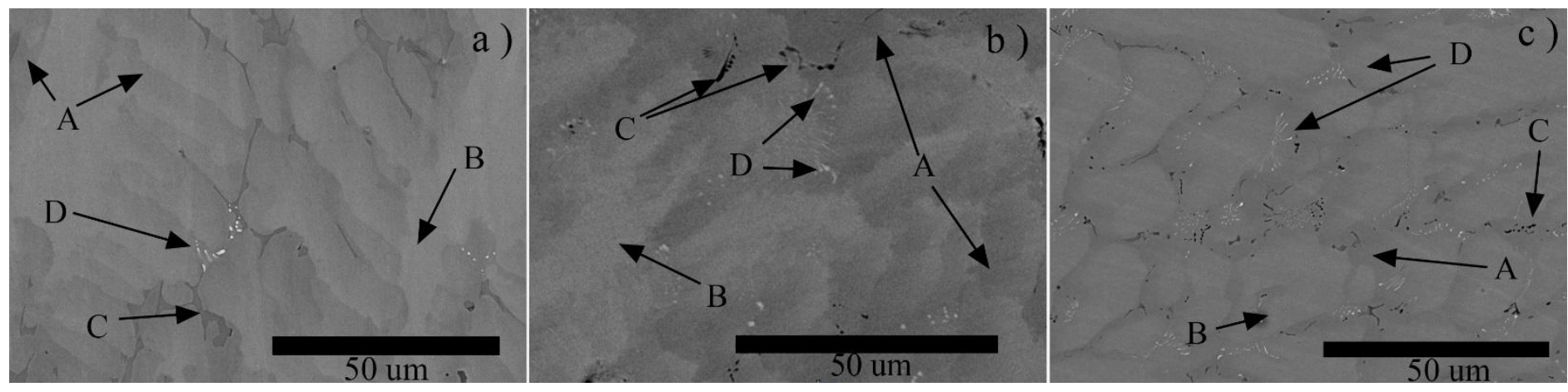

Fig.4. SEM-BSE images showing the microstructure of the three alloys. a) M1, b) M2 and c) M3. Labels stand for: A. dark zone, B. light zone, C. AB precipitate, $\mathrm{D} . \mathrm{ZrO}_{2}$.

As described in previous works with alloys of similar composition [43, 51], the sample is mainly composed by a mixture of two distinctive areas (light and dark presented in table 1 and shown in Fig.4) with different compositions. For M2 and M3 alloys, the two areas have close Mn content. However, for A-type elements, the light area exhibits higher $\mathrm{Zr}$ and lower $\mathrm{Ti}$ content than the nominal one. Similarly, for B-type elements, the light area has higher $\mathrm{Cr}$ and lower $\mathrm{V}$ than the nominal value. As for M1, the content of A-type elements $\mathrm{Zr}$ and Ti follow the same trend as in M2 and M3. However, the light area displays a high content of V leading to over stoichiometry in B-type elements as compared to the nominal value. This might be driven by the lack of $\mathrm{Cr}$ in this alloy. It has to be highlighted that despite of the different composition of light and dark zones, both phases crystallize in C14 laves phase with close lattice parameters as evidenced by the XRPD analysis. Furthermore, for the three alloys a $\mathrm{ZrO}_{2}$ (D label in Fig.3) and an $\mathrm{AB}$ type precipitate (C label at Fig. 3) were observed in small amount (less than $1 \%$ of surface images). Their influence on the thermodynamic properties can be neglected as compared to the effect of chemical changes observed in the alloy matrix (light and dark zones) [48, 52]. The determined chemical composition of $\mathrm{AB}$ precipitate for $\mathrm{M} 1$ is $\mathrm{Ti}_{0.985(6)} \mathrm{Zr}_{0.104(4)} \mathrm{Mn}_{0.817(6)} \mathrm{V}_{0.191(4)}$, while for $\mathrm{M} 2$ and $\mathrm{M} 3$ it is $\mathrm{Ti}_{0.94(4)} \mathrm{Zr}_{0.06(4)} \mathrm{Mn}_{0.50(6)} \mathrm{Cr}_{0.15(6)} \mathrm{V}_{0.093(4)}$. These secondary phases were not observed in XRPD patterns (Fig.3).

\subsection{Thermodynamic characterization and P-c-I modelling for numerical approach}

The P-c-I of the three alloys at 23,50 and $80{ }^{\circ} \mathrm{C}$ are displayed by symbols in Fig.5 a (M1), b (M2) and c (M3). Fits of the isotherm data to the Fang model are given both in absorption (solid line) and desorption (dash line). The experimental Van't Hoff plots determined from plateau pressures at a hydrogen content of $\approx 1 \mathrm{wt} \%$ for absorption (solid line) and desorption (dash line) are displayed in Fig.5d. 

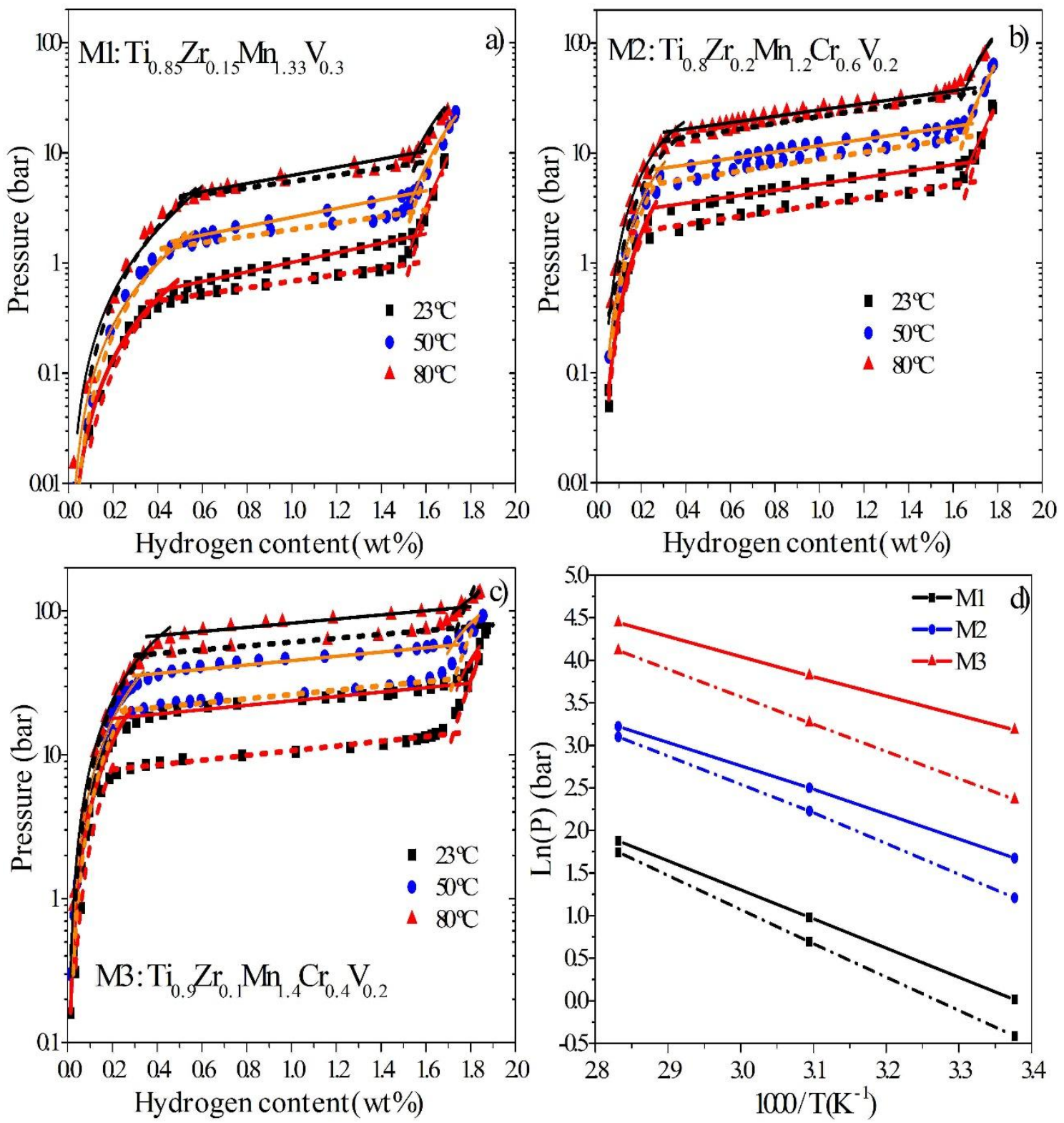

Fig.5. Thermodynamic properties of M1 (a), M2 (b) and M3 (c) alloys. Experimental P-c-I data in a-c are shown by symbols and the fits performed with the Fang model by lines. d) Derived Van't Hoff plots for absorption (solid line) and desorption (dash line).

Fig.5 shows that the Fang model provides a good fit of P-c-I data. All alloys exhibit sloping plateau which is attributed to the chemical heterogeneity of the alloys (Fig.4 and Table 2) [48] [52]. Furthermore, the hysteresis decreases with temperature for the three alloys (Fig.5 and table 3 ), which is in agreement with previous reports [53]. This reduction can be an advantage for the operation of the compressor, since the desorption and absorption pressure at high temperature would be closer, and this fact increases the CR and efficiency of the compressor [5]. Furthermore, the enthalpies and entropies of formation $(F)$ and dissociation (D) can be found in Table 3.

Table 3. Thermodynamic data of M1, M2 and M3

\begin{tabular}{|c|c|c|c|c|c|c|c|}
\hline & \multicolumn{3}{|c|}{ Hysteresis @ $\approx 1 \mathrm{wt} \%$} & \multirow{2}{*}{$\begin{array}{l}\text { Enthalpy } F \\
(\mathrm{~kJ} / \mathrm{mol})\end{array}$} & \multirow{2}{*}{$\begin{array}{l}\text { Entropy } \mathbf{F} \\
\left(\mathbf{J} / \mathbf{m o l}^{*} \mathbf{K}\right)\end{array}$} & \multirow{2}{*}{$\begin{array}{l}\text { Enthalpy D } \\
(\mathrm{kJ} / \mathrm{mol})\end{array}$} & \multirow{2}{*}{$\begin{array}{l}\text { Entropy } \\
\left(\mathrm{J} / \mathrm{mol}^{*} \mathbf{K}\right)\end{array}$} \\
\hline & $23^{\circ} \mathrm{C}$ & $50^{\circ} \mathrm{C}$ & $80^{\circ} \mathrm{C}$ & & & & \\
\hline M1 & 0.39 & 0.26 & 0.14 & $28 \pm 2$ & $96 \pm 2$ & $-33 \pm 1$ & $-107.8 \pm 0.1$ \\
\hline M2 & 0.44 & 0.28 & 0.14 & $24 \pm 1$ & $94 \pm 1$ & $-29 \pm 1$ & $-108 \pm 3$ \\
\hline M3 & 0.80 & 0.54 & 0.31 & $19.3 \pm 0.5$ & $91.3 \pm 0.2$ & $-27 \pm 1$ & $-110 \pm 2$ \\
\hline
\end{tabular}


The results in entropy and enthalpy obtained are in general agreement with previous studies on this type of materials $[38,50,54]$. The decrease in enthalpy (lower stability) follows closely the decrease in cell volume previously mentioned.

\subsection{Realistic thermodynamic simulation approach}

Fig.6 shows the thermodynamic simulation of the coupling between the three stages of a realistic MHHC compressor, i.e. after considering hysteresis and sloping plateau effects. The figure shows the operation points (O.P.) for absorption (solid squares) at $23^{\circ} \mathrm{C}$ and desorption (solid circles) at a given HT that fulfills the operational conditions described in section 2.3. HT was initially fixed to $110{ }^{\circ} \mathrm{C}$ for the three stages. P-c-I absorption curves at $23^{\circ} \mathrm{C}$ are experimental data (open symbols). P-c-I desorption curves at HT are simulations using Fang model (Fig. 5) at the temperature where the operation conditions are satisfied. The dot lines with arrows indicate the thermodynamic path followed by the MHHC compressor.

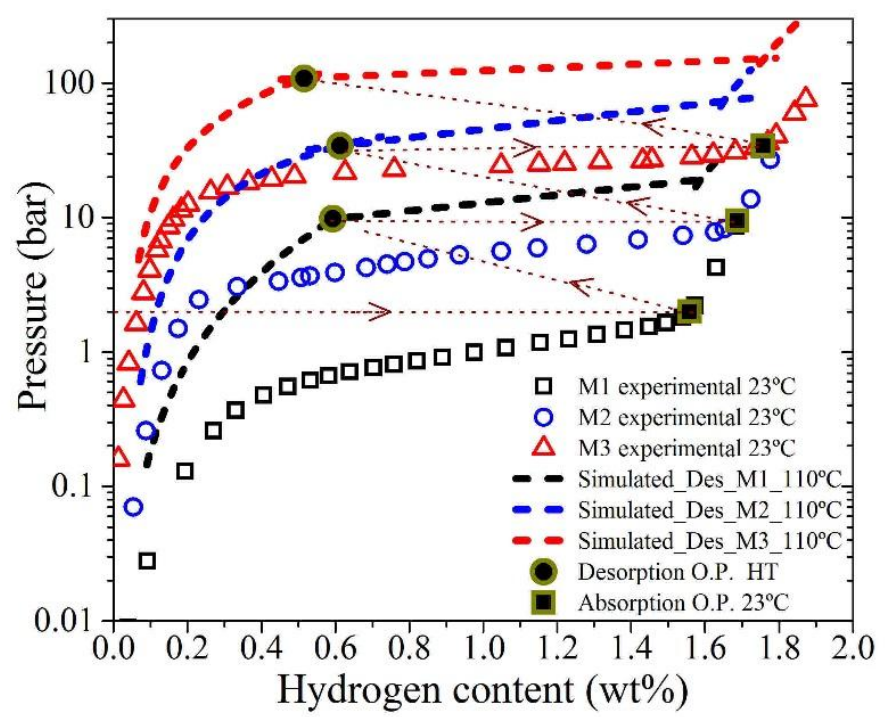

Fig.6. Thermodynamic simulation of the three stage MHHC. The solid squared points are the absorption O.P. for each stage. The solid circle points indicate the desorption O.P. The open symbols are the experimental data of each alloy at $23^{\circ} \mathrm{C}$, while the dash lines are the simulations of the P-c-I zones at $110^{\circ} \mathrm{C}$. The dot lines with arrows indicate the path followed by the three stage MHHC.

Several aspects of this simulation are worth discussing. The reversible capacity of each stage is comprised between $\beta_{\min }$ at RT and $\alpha_{\max }$ at HT. One should notice that $\alpha_{\max }$ increases and $\beta_{\min }$ decreases with temperature, so that the higher HT the lower the reversible capacity is [55]. For the first two stages, the HT should be above a certain value so that the desorption pressure of the initial stage is higher than the absorption pressure of the following stage. For instance, for HT1 $=110^{\circ} \mathrm{C}$, the desorption pressure attains 9.6 bar, which is higher than the absorption pressure at $23{ }^{\circ} \mathrm{C}$ of the second stage: 9.5 bar. Likewise, the same HT value for the second stage releases hydrogen at 34.1 bar, which is higher than the 33.9 bar of absorption pressure in the third stage at $23^{\circ} \mathrm{C}$. At these conditions, and, fixing also HT3 $=110{ }^{\circ} \mathrm{C}$, the reversible capacity for M1, M2 and M3 alloys are 0.97, 1.07 and $1.2 \mathrm{wt} \%$, respectively, with an output system pressure of 108.2 bar.

Furthermore, one should now consider that the desorption O.P. of the third stage influences the total CR and $\mathrm{n}_{\mathrm{H} 2-\mathrm{C}}$ of the system. To validate the influence of the HT3 temperature in these performances, three temperatures were analyzed: $110^{\circ} \mathrm{C}, 120^{\circ} \mathrm{C}$ and $132^{\circ} \mathrm{C}$. Table 4 present the main results achieved with the different temperatures studied. 
Table 4. Main parameters achieved with the HT3 variation

\begin{tabular}{cccc}
\hline HT3 $\left({ }^{\circ} \mathbf{C}\right)$ & $\mathbf{P}_{\text {des }}($ bar $)$ & $\begin{array}{c}\text { Reversible capacity } \\
(\text { wt. \%) }\end{array}$ & CR \\
\hline 110 & 108.2 & 1.2 & 54.3 \\
120 & 137.7 & 1.15 & 69.1 \\
132 & 183.2 & 0.98 & 92 \\
\hline
\end{tabular}

As the HT3 temperature rises, the CR gradually increases from 54.3 to 92 , considering that $P_{\text {des }}$ is an increasing function of temperature. The $\mathrm{n}_{\mathrm{H} 2-\mathrm{C}}$ depends mainly on two parameters of the design, the reversible capacity and the $\mathrm{P}_{\text {des }}$ of the third stage, which are largely dependent on

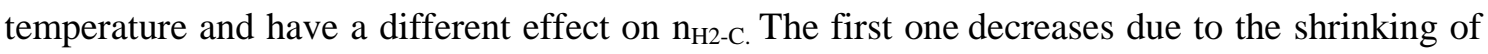
the two-phase $\alpha+\beta$ miscibility on approaching the critical temperature (Fig.6) [55], leading to a modest decrease in the moles compressed. On the other hand, the $\mathrm{P}_{\text {des }}$ increases exponentially with temperature, allowing for an increase in $\mathrm{n}_{\mathrm{H} 2-\mathrm{C}}$ as shown in Fig.7. Furthermore, besides the third stage temperature HT3, the $\mathrm{V}_{\text {ext }}$ to which the hydrogen gas is compressed, is of critical importance as it determinates to a large extent the $\mathrm{n}_{\mathrm{H} 2-\mathrm{C}}$ of the system. This is evidenced in Fig.7, showing that this magnitude linearly depends on the $V_{\text {ext }}$.

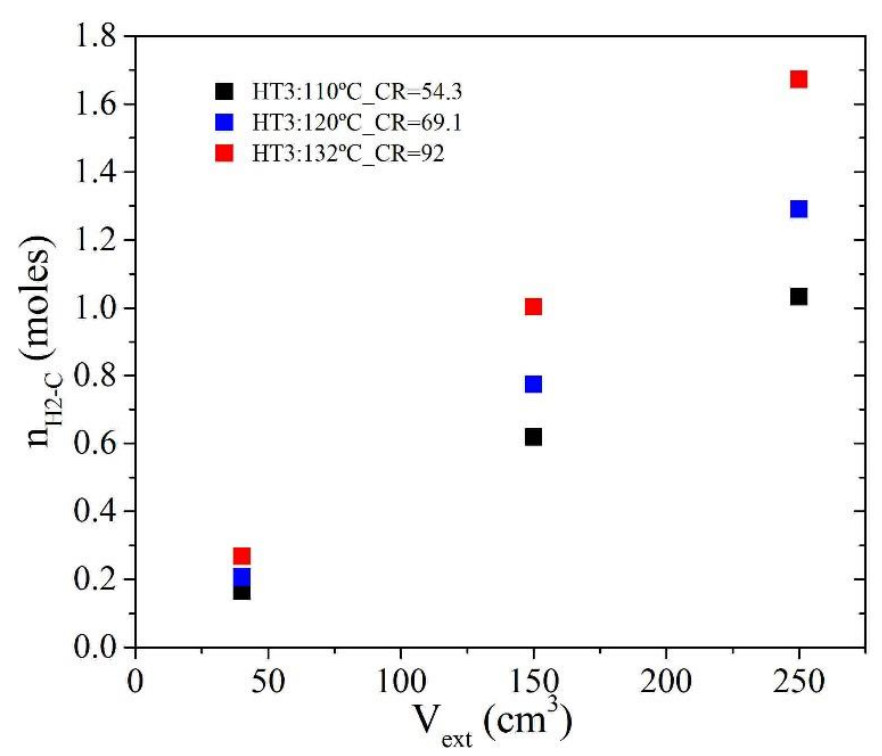

Fig.7. $n_{H 2-C}$ as a function of the $V_{\text {ext }}$ for three HT3 desorption temperatures.

As expected, the best $\mathrm{CR}$ (92) and the highest amount of $\mathrm{n}_{\mathrm{H} 2-\mathrm{C}}(1.672)$ were achieved at the highest desorption temperature $\left(132^{\circ} \mathrm{C}\right)$ and the largest $\mathrm{V}_{\text {ext }}\left(250 \mathrm{~cm}^{3}\right)$ studied. The enhancement of both performances benefit from the exponential grow of the plateau pressure with temperature even if the reversible capacity is reduced. Therefore, on increasing HT3 both the $\mathrm{CR}$ of the system and $\mathrm{n}_{\mathrm{H} 2-\mathrm{C}}$ increase. Indeed, the used methodology constraints the O.P. in the first and second stages to the variations in the last stage of compression. Then, the $\mathrm{m}$ and SVol are determined by HT3, leading to the best operational characteristics of the compressor. 


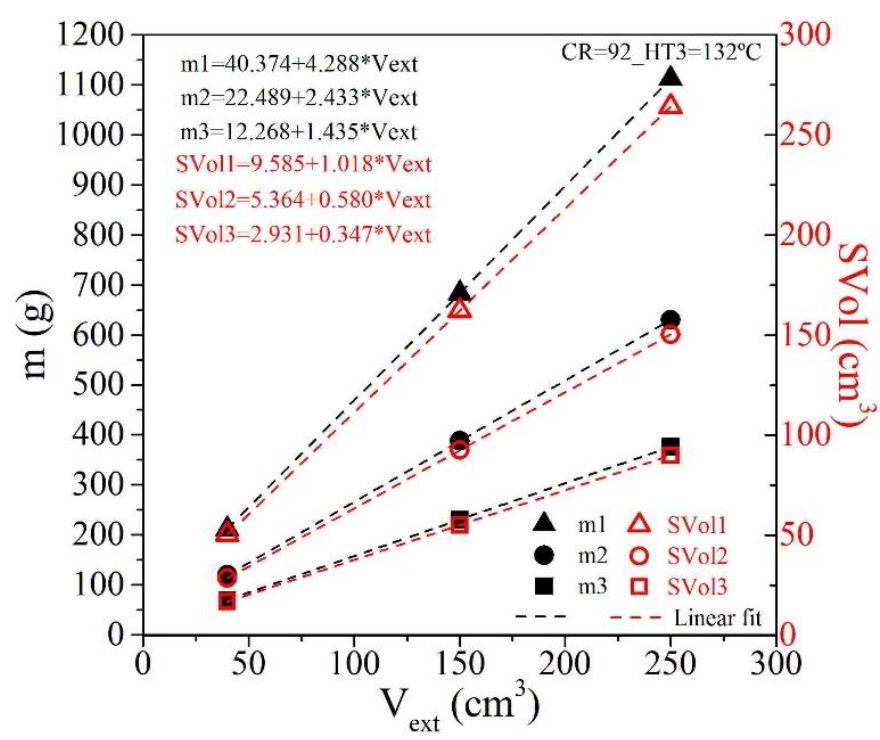

Fig.8. Dependence of alloy mass (left-axis) and vessel volume of each stage (right-axis) with $\mathrm{V}_{\text {ext }}$ for HT3 = $132^{\circ} \mathrm{C}$. Inset equations stand for the best linear fits

Fig.8 shows the dependence of the alloy mass and vessel volume at each stage on $V_{\text {ext }}$ for HT3 $=$ $132{ }^{\circ} \mathrm{C}$. Both magnitudes can be fitted with linear equations (given in the figure) that depend on $\mathrm{V}_{\text {ext }}$. The optimum alloy masses scale approximately in the ratio 3:2:1 for the first, second and third stages, respectively. The link between these parameters derive from the thermodynamic simulations shown in Fig.6. The given linear fits can be extrapolated to any external vessel volume at the given operation conditions. A summary of the optimized operating parameters of the MHHC system is displayed in Table 5.

Table 5. Summary of the operating system parameters found during the simulation

\begin{tabular}{|c|c|c|c|c|c|c|}
\hline \multirow{3}{*}{ Stage } & \multirow{3}{*}{$\begin{array}{c}\mathbf{P}_{\text {abs }}(\text { bar }) / / \\
\text { RT }\left({ }^{\circ} \mathbf{C}\right)\end{array}$} & \multirow{3}{*}{$\begin{array}{c}\mathbf{P}_{\text {des }}(\text { bar }) / / \\
\text { HT }\left({ }^{\circ} \mathbf{C}\right)\end{array}$} & \multirow{3}{*}{$\begin{array}{c}\text { Reversable } \\
\text { capacity } \\
\text { (wt.\%) }\end{array}$} & \multicolumn{3}{|c|}{$\mathbf{m}(\mathbf{g}) / / \mathrm{SVol}\left(\mathrm{cm}^{3}\right)$} \\
\hline & & & & \multicolumn{3}{|c|}{ At $V_{\text {ext }}\left(\mathrm{cm}^{3}\right)$} \\
\hline & & & & 40 & 150 & 250 \\
\hline 1 & $1.99 / / 23$ & $9.6 / / 110$ & 0.97 & $212 / / 50.3$ & $684 / / 162$ & $1112 / / 264$ \\
\hline 2 & $9.5 / / 23$ & $34.1 / / 110$ & 1.07 & $120 / / 28.6$ & $388 / / 92$ & $631 / / 150$ \\
\hline 3 & $33.9 / / 23$ & $183 / / 132$ & 0.98 & $70.5 / / 16.8$ & $230 / / 55.3$ & $376 / / 89.8$ \\
\hline
\end{tabular}

Alloy masses and stage volumes given in table 4 result from the optimization of thermodynamic parameters (e.g. compression ratio and desorption temperature) of the third stage. Nevertheless, a further kinetic analysis will be needed to better optimize the system operation and design to attain the highest efficiency and COP of the system [5].

It is not straightforward to compare our simulation results to previous works because they are very sensitive to system design (volumes and masses of alloys) and operation temperatures. However, for similar temperatures of operation, between RT and $130^{\circ} \mathrm{C}, \mathrm{CR}$ values between 3 and 75 have been reported for other MHHC prototypes [5]. Our results are at the top of this range.

The results of this realistic thermodynamic approach differ in several aspects from those of the ideal first approach. First, the nominal composition of the alloys could not be exactly obtained after their synthesis due to the different volatility of the raw materials, as well as to the intrinsic tendency of $\mathrm{TiMn}_{2}$-type compounds to yield chemical inhomogeneity. This proves that simulations will be more precise when they are based in experimental data from real materials. Second, absorption pressures at each stage using real experimental data were observed to differ 
from that predicted for the ideal ones in the first approach. For instance, for M1 alloy, the experimental absorption pressure at $23^{\circ} \mathrm{C}$ and $\beta_{\min }$ is higher $(1.99$ bar) than that predicted by the first approach (1.4 bar). Analogous deviations are found for M2 and M3 alloys. This variation results from the sloping nature of the plateau pressure which is not considered in the ideal Van't Hoff plots [5, 51]. Indeed, the increase in the real absorption pressure at each stage requires a correlated increase in the desorption temperature of the previous one. As compared to an ideal thermodynamic model with flat plateau, the realistic one gives rise to a substantial increase (between 30 and $50^{\circ} \mathrm{C}$, depending on the stage) in the desorption temperatures, thus affecting to the total energy consumption of the MHHC. Third, as concerns hysteresis effects, their influence on the operational parameters is lower than that induced by the sloping plateau. In fact, the hysteresis tends to be reduced when increasing the temperature [53]. Fourth, the realistic simulation takes into account the dependence of the $\alpha_{\max }$ and $\beta_{\min }$ phase limits with the temperature. As the $\alpha+\beta$ region shrinks, the reversible capacity decreases, leading to the necessity of increasing the alloy mass at each compression stage. As a last remark, it is worth noting that even if the evidenced realistic features induce significant changes in the operation conditions of the system, the selection of the three initial alloys by the first approach remains valid. This results from the fact that thermodynamic correlations between the pairs of materials designated remains roughly the same.

\section{Conclusions}

Three $\quad \mathrm{AB}_{2}$ compounds $\left(\mathrm{M} 1: \quad \mathrm{Ti}_{0.85} \mathrm{Zr}_{0.15} \mathrm{Mn}_{1.33} \mathrm{~V}_{0.3}, \quad \mathrm{M} 2: \quad \mathrm{Ti}_{0.8} \mathrm{Zr}_{0.2} \mathrm{Mn}_{1.2} \mathrm{Cr}_{0.6} \mathrm{~V}_{0.2}, \quad \mathrm{M} 3\right.$ : $\mathrm{Ti}_{0.9} \mathrm{Zr}_{0.1} \mathrm{Mn}_{1.47} \mathrm{Cr}_{0.4} \mathrm{~V}_{0.2}$ ) have been selected from literature thermodynamic data in order to be used in a three stage MHHC. A realistic thermodynamic model that uses experimental thermodynamic data and real equation of state for $\mathrm{H}_{2}$ gas were used to provide a more precise simulation of the MHHC operation parameters. This model allows to determine the optimal operational temperature, alloy mass and vessel volume at each stage. The realistic thermodynamic features of hydride formation and decomposition (sloping plateau, hysteresis and dependence of $\alpha+\beta$ miscibility gap with temperatures) have an important effect on the optimal values of these operational parameters. In particular, for a given inlet pressure and final compression ratio, the desorption temperature and alloy mass at each compression stage are significantly higher than those obtained with an ideal model for hydride formation and decomposition (i.e., flat plateau, no hysteresis and constant miscibility gap). A further heat and mass transfer and hydrogen sorption semi-empirical kinetic analysis has to be performed in order to optimize the operability of the system in dynamic conditions.

\section{Acknowledgements}

The authors thank the Spanish MINECO/FEDER for financial support under contract (MAT2015-65203-R) and Mr. F. Moreno and F. Couturas for technical assistance. One of the authors (A.R. Galvis E) would like to thank the Colombian Government and the Administrative Department of Science, Technology and Innovation -Colciencias-, for the financial support under contract 568.

\section{References}

[1] Mellouli S, Askri F, Dhaou H, Jemni A, Ben Nasrallah S. Numerical simulation of heat and mass transfer in metal hydride hydrogen storage tanks for fuel cell vehicles. Int $\mathbf{J}$ Hydrog Energy 2010;35:1693-705. doi:10.1016/j.ijhydene.2009.12.052.

[2] Zheng J, Liu X, Xu P, Liu P, Zhao Y, Yang J. Development of high pressure gaseous hydrogen storage technologies. Int J Hydrog Energy 2012;37:1048-57. doi:10.1016/j.ijhydene.2011.02.125.

[3] Marchenko OV, Solomin SV. The future energy: Hydrogen versus electricity. Int J Hydrog Energy 2015;40:3801-5. doi:10.1016/j.ijhydene.2015.01.132.

[4] Ball M, Wietschel M. The future of hydrogen - opportunities and challenges 2 . Int J Hydrog Energy 2009;34:615-27. doi:10.1016/j.ijhydene.2008.11.014. 
[5] Lototskyy MV, Yartys VA, Pollet BG, Bowman RC. Metal hydride hydrogen compressors: A review. Int J Hydrog Energy 2014;39:5818-51.

doi:10.1016/j.ijhydene.2014.01.158.

[6] Park J-G, Jang K-J, Lee PS, Lee J-Y. The operating characteristics of the compressordriven metal hydride heat pump system. Int J Hydrog Energy 2001;26:701-706.

[7] Bhuiya MMH, Kumar A, Kim KJ. Metal hydrides in engineering systems, processes, and devices: A review of non-storage applications. Int J Hydrog Energy 2015;40:2231-47. doi:10.1016/j.ijhydene.2014.12.009.

[8] Hardy BJ, Anton DL. Hierarchical methodology for modeling hydrogen storage systems. Part I: Scoping models. Int J Hydrog Energy 2009;34:2269-77. doi:10.1016/j.ijhydene.2008.12.070.

[9] Førde T, Næss E, Yartys VA. Modelling and experimental results of heat transfer in a metal hydride store during hydrogen charge and discharge. Int J Hydrog Energy 2009;34:5121-30. doi:10.1016/j.ijhydene.2009.03.019.

[10] Gkanas EI, Grant DM, Stuart AD, Eastwick CN, Book D, Nayebossadri S, et al. Numerical study on a two-stage Metal Hydride Hydrogen Compression system. J Alloys Compd 2015;645:S18-22. doi:10.1016/j.jallcom.2015.03.123.

[11] Laurencelle F, Dehouche Z, Morin F, Goyette J. Experimental study on a metal hydride based hydrogen compressor. J Alloys Compd 2009;475:810-6. doi:10.1016/j.jallcom.2008.08.007.

[12] Vanhanen JP, Hagström MT, Lund PD. Combined hydrogen compressing and heat transforming through metal hydrides. Int J Hydrog Energy 1999;24:441-448.

[13] Wang X, Liu H, Li H. A 70 MPa hydrogen-compression system using metal hydrides. Int J Hydrog Energy 2011;36:9079-85. doi:10.1016/j.ijhydene.2011.04.193.

[14] Lototsky M, Klochko Y, Linkov V, Lawrie P, Pollet BG. Thermally Driven Metal Hydride Hydrogen Compressor for Medium-Scale Applications. Energy Procedia 2012;29:347-56. doi:10.1016/j.egypro.2012.09.041.

[15] Bhuiya MMH, Lee CY, Hwang T, Munira S, Hopkins R, Yoon H, et al. Experimentally tuned dual stage hydrogen compressor for improved compression ratio. Int J Hydrog Energy 2014;39:12924-33. doi:10.1016/j.ijhydene.2014.05.186.

[16] Muthukumar P, Prakashmaiya M, Srinivasamurthy S. Performance tests on a thermally operated hydrogen compressor. Int J Hydrog Energy 2008;33:463-9. doi:10.1016/j.ijhydene.2007.07.019.

[17] Yartys VA, Lototskyy M, Linkov V, Grant D, Stuart A, Eriksen J, et al. Metal hydride hydrogen compression: recent advances and future prospects. Appl Phys A 2016;122. doi:10.1007/s00339-016-9863-7.

[18] Voskuilen TG, Waters EL, Pourpoint TL. A comprehensive approach for alloy selection in metal hydride thermal systems. Int J Hydrog Energy 2014;39:13240-54. doi:10.1016/j.ijhydene.2014.06.119.

[19] Hagstrom MT, Lund PD, Vanhanen JP, others. Metal hydride hydrogen storage for nearambient temperature and atmospheric pressure applications, a PDSC study. Int J Hydrog Energy 1995;20:897-909.

[20] Capurso G, Schiavo B, Jepsen J, Lozano G, Metz O, Saccone A, et al. Development of a modular room-temperature hydride storage system for vehicular applications. Appl Phys A 2016;122. doi:10.1007/s00339-016-9771-x.

[21] Huang T, Wu Z, Sun G, Xu N. Microstructure and hydrogen storage characteristics of TiMn2-XVX alloys. Intermetallics 2007;15:593-8. doi:10.1016/j.intermet.2006.10.035.

[22] Zotov TA, Romanov IA, Mitrokhin SV, Verbetsky VN, Pertii OA. Electrochemical And Hydrogen Sorption Properties of Ab5-Type Alloys Where A-La, Ce; B-Ni, Co, Mn, $\mathrm{Fe}, \mathrm{Cu}, \mathrm{Cr}, \mathrm{Al}$. Carbon Nanomater. Clean Energy Hydrog. Syst., Springer; 2008, p. 523532.

[23] Dehouche Z, Grimard N, Laurencelle F, Goyette J, Bose TK. Hydride alloys properties investigations for hydrogen sorption compressor. J Alloys Compd 2005;399:224-36. doi:10.1016/j.jallcom.2005.01.029. 
[24] Iosub V, Latroche M, Joubert J-M, Percheron-Guégan A. Optimisation of MmNi5-xSnx $(\mathrm{Mm}=\mathrm{La}, \mathrm{Ce}, \mathrm{Nd}$ and $\mathrm{Pr}, 0.27<\mathrm{x}<0.5)$ compositions as hydrogen storage materials. Int $\mathrm{J}$ Hydrog Energy 2006;31:101-8. doi:10.1016/j.ijhydene.2005.02.004.

[25] Rożdżyńska-Kiełbik B, Iwasieczko W, Drulis H, Pavlyuk V., Bala H. Hydrogenation equilibria characteristics of LaNi5-xZnx intermetallics. J Alloys Compd 2000;298:23743. doi:09258388.

[26] Bereznitsky M, Jacob I, Bloch J, Mintz M. Thermodynamic and structural aspects of hydrogen absorption in the $\mathrm{Zr}(\mathrm{AlxCo1-x}) 2$ system. J Alloys Compd 2002;346:217-21. doi:10.1016/S0925-8388(02)00670-9.

[27] Bereznitsky M, Jacob I, Bloch J, Mintz M. Thermodynamic and structural aspects of hydrogen absorption in the $\mathrm{Zr}(\mathrm{AlxFe} 1-\mathrm{x}) 2$ system. J Alloys Compd 2003;351:180-3. doi:10.1016/S0925-8388(02)01074-5.

[28] Lijun L, Honghui C, Xingbo H, Guanhong L, Xiaoxing T, Chengbin W, et al. Structures and Hydrogen Storage Properties of La1-xMgxNi4.25Al0.75 ( $\mathrm{x}=0.0,0.1,0.2,0.3$ ) Alloys. Rare Met Mater Eng 2016;45:56-61. doi:10.1016/S1875-5372(16)30046-7.

[29] Dantzer P. Static, dynamic and cycling studies on hydrogen in the intermetallics LaNi5 and LaNi4. 77Al0. 22. J Common Met 1987;131:349-363.

[30] Borzone EM, Baruj A, Blanco MV, Meyer GO. Dynamic measurements of hydrogen reaction with LaNi5-xSnx alloys. Int J Hydrog Energy 2013;38:7335-43. doi:10.1016/j.ijhydene.2013.04.035.

[31] Pickering L, Reed D, Bevan AI, Book D. Ti-V-Mn based metal hydrides for hydrogen compression applications. J Alloys Compd 2015;645:S400-3. doi:10.1016/j.jallcom.2014.12.098.

[32] Kumar V, Pukazhselvan D, Tyagi AK, Singh SK. Hydrogen absorption/desorption characteristics of room temperature $\mathrm{ZrMn} 2-\mathrm{xNix}$ system $(\mathrm{x}=1 \cdot 25-1 \cdot 50)$. Bull Mater Sci 2014;37:655-660.

[33] Mitrokhin SV, Bezuglaya TN, Verbetsky VN. Structure and hydrogen sorption properties of (Ti, Zr)-Mn-V alloys. J Alloys Compd 2002;330:146-151.

[34] Wallace WE, Pourarian F. Hydrogen storage materials of hyperstoichiometric alloys. US4512965A, 1985.

[35] Lototsky MV, Yartys VA, Zavaliy IY. Vanadium-based BCC alloys: phase-structural characteristics and hydrogen sorption properties. J Alloys Compd 2005;404-406:421-6. doi:10.1016/j.jallcom.2005.01.139.

[36] Kapischke J, Hapke J. Measurement of the pressure-composition isotherms of high temperature and low-temperature metal hydrides. Exp Therm Fluid Sci 1998;18:70-81. doi:10.1016/S0894-1777(98)10007-9.

[37] Guo X, Wang S, Liu X, Li Z, Lü F, Mi J, et al. Laves phase hydrogen storage alloys for super-high-pressure metal hydride hydrogen compressors. Rare Met 2011;30:227-31. doi:10.1007/s12598-011-0373-7.

[38] Anikina EY, Verbetsky VN. Investigation of the hydrogen interaction with Ti0.9Zr0.1Mn1.3V0.7 by means of the calorimetric method. Int J Hydrog Energy 2016;41:11520-5. doi:10.1016/j.ijhydene.2015.12.126.

[39] Park J-M, Lee J-Y. Hydrogenation characteristics of the Zr1-xTixCr1-yFe1+y laves phase alloys. J -Common Met 1990;160:259-71. doi:10.1016/0022-5088(90)90386-X.

[40] Joubert J-M. A Calphad-type equation of state for hydrogen gas and its application to the assessment of Rh-H system. Int J Hydrog Energy 2010;35:2104-11. doi:10.1016/j.ijhydene.2010.01.006.

[41] Fang, S., Zhou, Z., Zhang, J., Yao, M., Feng, F., Northwood, D.O. The application of mathematical models to the calculation of selected hydrogen storage properties (formation enthalpy and hysteresis) of AB2-type alloys. Int J Hydrog Energy 2000;25:143-9. doi:10.1016/S0360-3199(99)00032-4.

[42] Payá J, Linder M, Laurien E, Corberán JM. Mathematical models for the P-C-T characterization of hydrogen absorbing alloys. J Alloys Compd 2009;484:190-5. doi:10.1016/j.jallcom.2009.05.069. 
[43] Galvis Escobar AR, Chaise A, Iosub V, Salque B, Fernandez JF, Gillia O. Stress effect on the swelling/shrinking behavior of an $\mathrm{AB} 2$ alloy during hydrogenation cycles. Int $\mathrm{J}$ Hydrog Energy 2017;42:22422-31. doi:10.1016/j.ijhydene.2017.03.145.

[44] Morita Y, Gamo T, Kuranaka S. Effects of nonmetal addition on hydriding properties for Ti-Mn Laves phase alloys. J Alloys Compd 1997;253:29 -33. doi:10.1016/S09258388(96)03056-3.

[45] Bobet J-L, Darriet B. Relationship between hydrogen sorption properties and crystallography for TiMn2 based alloys. Int J Hydrog Energy 2000;25:767-72. doi:10.1016/S0360-3199(99)00101-9.

[46] Bobet J-L, Chevalier B, Darriet B. Crystallographic and hydrogen sorption properties of TiMn 2 based alloys. Intermetallics 2000;8:359-363.

[47] Villars P, Calvert LD. Pearson's handbook of crystallographic data for intermetallic phases. vol. 1-3. Metals Park. Ohio.: American Society for Metals.; 1986.

[48] Mitrokhin SV. Regularities of hydrogen interaction with multicomponent $\mathrm{Ti}(\mathrm{Zr})-\mathrm{Mn}-\mathrm{V}$ Laves phase alloys. J Alloys Compd 2005;404-406:384-7. doi:10.1016/j.jallcom.2005.02.078.

[49] Fang F, Yongtao L, Qingan Z, Liangliang S, Zongping S, Dalin S. Hydrogen storage properties of TiMn1.5V0.2-based alloys for application to fuel cell system. J Power Sources 2010;195:8215-8221. doi:10.1016/j.jpowsour.2010.06.059.

[50] Liu B-H, Kim D-M, Lee K-Y, Lee J-Y. Hydrogen storage properties of TiMn2-based alloys. J Alloys Compd 1996;240:214-8. doi:10.1016/0925-8388(96)02245-1.

[51] Galvis E. AR, Leardini F, Bodega J, Ares JR, Fernandez JF. Realistic simulation in a single stage hydrogen compressor based on AB2 alloys. Int J Hydrog Energy 2016;41:9780-8. doi:10.1016/j.jhydene.2016.01.125.

[52] Shudo Y, Ebisawa T, Itoh H. Characterization of Ti-Zr-Mn-V-based Laves phase alloys for MH refrigeration system. J Alloys Compd 2003;356:497-500.

[53] Qian S, Northwood DO. Hysteresis in metal-hydrogen systems: a critical review of the experimental observations and theoretical models. Int J Hydrog Energy 1988;13:25-35.

[54] Gamo,T., Moriwaki, Y., Yanagihara, N., Yamashita, T., Iwaki,T. Formation and properties of Titanium-Manganese alloy hydrides. Int J Hydrog Energy 1985;10:39-47. doi:10.1016/0360-3199(85)90134-X.

[55] Sandrock G. Hydrogen-metal systems. Hydrog. Energy Syst., Springer; 1995, p. 135-166. 